\title{
Effect of vibratory welding process on hardness of dissimilar welded joints
}

\author{
J. Kalpana ${ }^{a}$, P. Srinivasa $\operatorname{Rao}^{b}$ and P. Govinda Rao ${ }^{c^{*}}$
}

${ }^{a}$ Assistant Professor, Dept. of Mechanical Engineering, SSCE, Chilakapalem, Andhra Pradesh, India

${ }^{b}$ Professor, Dept. of Mechanical Engineering, Centurion University, Parlakhemundi, Odisha, India

${ }^{c}$ Associate Professor, Dept. of Mechanical Engineering, GMRIT, Rajam, Andhra Pradesh, India

\section{A B S T R A C T}

This paper presents the effect of vibratory dissimilar TIG (Tungsten Inert Gas) welding process on hardness of welded joins with respect to change of vibratory parameters. In this study, new vibratory setup with two metal engravers is used to give mechanical vibrations to the specimens to be welded. Finally, the effect of mechanical vibrations with the variation of vibration parameters is studied on the hardness at the weld bead and heat effected zone (HAZ) of welded joints.

\section{Introduction}

To overcome the disadvantages in normal welding process, vibratory assisted welding has been introduced for improving mechanical properties of welded joints. In vibratory welding, a force is applied periodically to the specimens during welding process. Due to this periodic force, weld pool is stirred to refine the grain structure in order to enhance the weld joint properties. Lu et al. (2007) investigated to improve the quality of full welded valve by the application of vibratory weld conditioning (VWC) and the effect of VWC on the welded joint properties was studied. In their study, cylinders with different thicknesses have been welded by submerged arc welding (SAW) and the experiment results showed that the vibration applied during welding reduces the residual deformation and stress. The yield strength, as well as the tensile strength, does not change distinctively in vibratory SAW (V-SAW) when compared with that in normal SAW (N-SAW), but the bend property was improved in V-SAW. They also conducted fracture toughness tests using single edge notch bend

* Corresponding author.

E-mail addresses: govind09.p@gmail.com (P.Govinda Rao) 
(SENB) specimens and demonstrated that the fracture surfaces of failed weld metal (WM) specimens are characterized by dimple-like structures. The depth and the density of these dimples are increased after the vibration applied in welding. River marking, the characteristic of cleavage fracture, is observed in the heat-affected zone (HAZ) specimens.

Teng et al. (2002) showed that the stress concentrations usually occur at structural geometry discontinuities, e.g. weld toes, and crack like defects. These stress concentration sites may serve for crack initiation and cracks that are propagating may lead to failure. Rao et al. (2015a) proposed a new vibratory welding technique for inducing mechanical vibrations into the weld pool during welding process. The designed vibratory setup produces the required vibrations at frequency with the amplitude and acceleration in terms of voltages. An increase in the flexural strength, impact strength, ultimate tensile strength and hardness of the weld pieces at the heat affected zone (HAZ) is observed. The increase in mechanical properties is attributed to, as the weld pool solidifies, grains are not only limited in size but also dendrites are broken before they grow large in size and forms refined microstructure. This mechanism is responsible for the improvement in flexural strength, ultimate tensile strength, impact strength and hardness of welded joints. From the experimental results it is clear that the mechanical properties are improved considerably with the increase in the acceleration and amplitude of the specimens. Mechanical properties are improved with rise in the input voltage and vibration period.

Munsi et al. (2001) investigated the influence of vibratory treatment on the fatigue life of welds by comparing with thermal stress relief. Xu et al. (2007) compared VWC and normal submerged arc welding of multi pass girth-butt welded pipes. They found that VWC can reduce the residual hoop stresses at the outer surface and the radial distortion significantly. Liu et al. (2013) addressed vibration responses of railway steel bridge considering welding residual stress based on a reasonable heat source model. Jurčius et al. (2010) investigated the effects of vibration energy input on stress concentration in weld and Heat Affected Zone of S355J2 steel and observed that by re-distributing the internal residual stress of welded structures, stress concentration can be reduced effectively. Rao et al. (2014a) used the vibratory setup to induce the mechanical vibrations to the weld pool during welding. Due to vibratory welding process, improvement of mechanical properties was observed. It was concluded that the refined microstructure mechanism was responsible for the improvement of impact strength. Rao et al. (2015b) designed a vibratory set up to induce mechanical vibrations into the weld pool during welding. As the weld pool solidifies, vibratory set up produces the mechanical vibrations. Due to this dendrites were broken up into smaller grains which lead to the improvement of flexural strength of welded joints.

Govindarao et al. (2012) employed a dynamic solidification technology to induce the mechanical vibrations during welding of butt welded joints. It was concluded that butt welded joints prepared under vibratory conditions possessed high hardness without any loss of its ductility. Rao et al. (2013, 2014b, 2015c) studied the strength of butt welded joints prepared by employing this technique. It was presumed that butt welded joints arranged under vibratory conditions had high hardness with no loss of its ductility. Authors utilized the vibratory setup to affect the mechanical vibrations to the weld pool amid welding. Because of vibratory welding process, change of mechanical properties has been observed. It was inferred that the refined microstructure component was in charge of the change of impact strength, tensile strength, flexural strength and hardness of butt welded joints of mild steel plates. Authors observed that post weld vibratory treatment will not influence the crystal structure, the increase in all properties are related to the crystal structure only. Finally, General regression neural network technique (GRNN) based tool has been developed for estimating tensile strength, impact strength, flexural strength and hardness for given input parameters.

Based on the past literature most of researchers have concentrated on improvement of mechanical properties of vibratory welded joints for similar metals. So that authors made an attempt to weld dissimilar plates by vibratory TIG welding process for observing hardness of weld bead region and heat affected regions with respect to change of vibratory parameters. 


\section{Experimental work}

Gas tungsten arc welding (GTAW), also known as tungsten inert gas (TIG) welding, is an arc welding process that uses a non-consumable tungsten electrode to produce the weld. The weld area is protected from atmospheric contamination by an inert shielding gas (argon or helium), and a filler metal is normally used, though some welds, known as autogenous welds, do not require it. A constantcurrent welding power supply produces electrical energy, which is conducted across the arc through a column of highly ionized gas and metal vapors known as a plasma. GTAW is most commonly used to weld thin sections of stainless steel and non-ferrous metals such as aluminum, magnesium, and copper alloys. The process grants the operator greater control over the weld than competing processes such as shielded metal arc welding and gas metal arc welding, allowing for stronger, higher quality welds. However, GTAW is comparatively more complex and difficult to master, and furthermore, it is significantly slower than most other welding techniques. A related process, plasma arc welding, uses a slightly different welding torch to create a more focused welding arc and as a result is often automated.

\subsection{Materials used}

Mild steel and Stainless steel plates with $5 \mathrm{~mm}$ thick have been used for vibratory TIG welding process. Mild Steel (Grade 1018 M S) is composed of (in weight percentage) 0.18\% Carbon (C), 0.6$0.9 \%$ Manganese $(\mathrm{Mn})$, maximum $0.04 \%$ Phosphorus $(\mathrm{P})$, maximum $0.05 \%$ Sulphur $(\mathrm{S})$ and the base metal Iron (Fe). Stainless steel (Grade $304 \mathrm{~S} \mathrm{~S}$ ) is composed of Chromium (Cr) ranging from 18-20\%, Nickel(Ni) ranging from 8-10.5\% and Carbon 0.08\%. Filler material (Grade ER 309L) is composed of Carbon $0.032 \%$, Manganese $1.26 \%$, Silicon $0.65 \%$, Phosphorous $0.028 \%$ and Sulphur $0.012 \%$.

\subsection{Vibratory welding setup}

Fig. 1 shows new vibratory welding setup, on which TIG vibratory dissimilar welding has been carried out for different frequencies of 600,800 and $1000 \mathrm{~Hz}$.

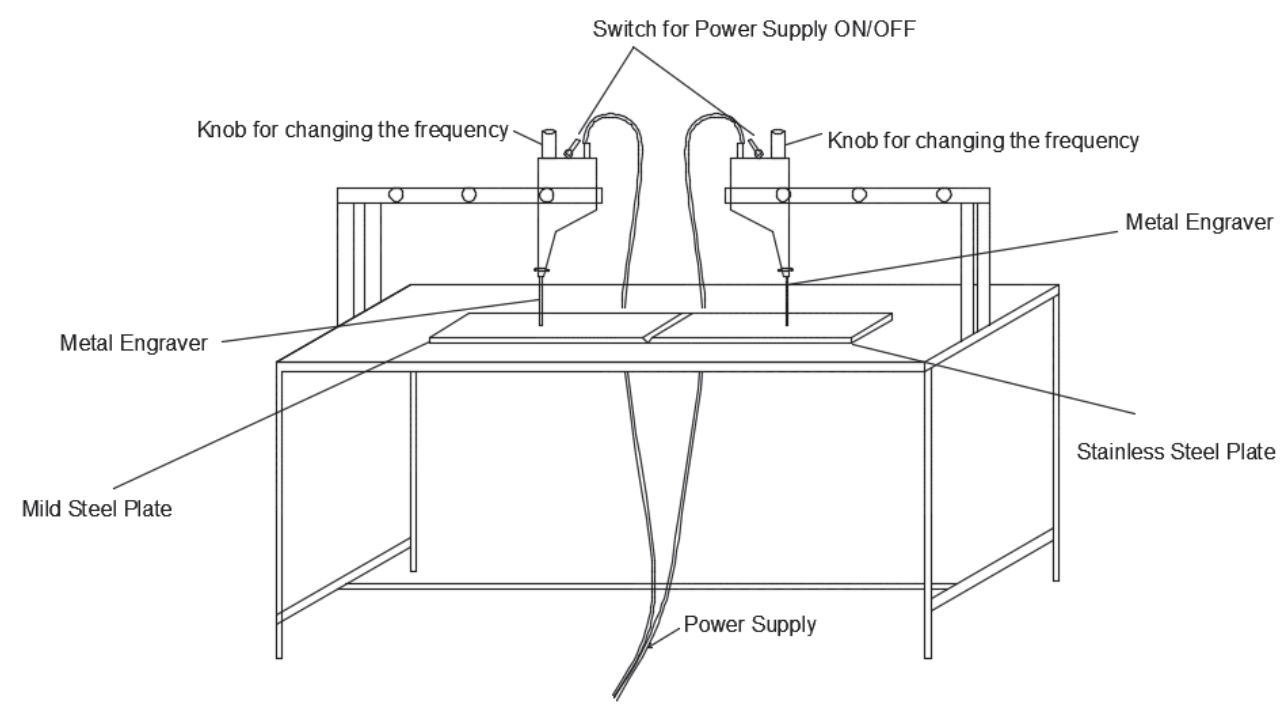

Fig. 1. Schematic diagram of vibration equipment setup.

This setup consists of two metal engravers as shown in Fig.1, transfers vibrations to specimens during welding. Metal engravers are worked on the principle of electro-dynamic force, which coverts electrical signals in to mechanical vibrations. Frequency of specimens can be adjusted by the rotation of knob provided on the metal engraver, which is shown in Fig.1. Frequency of specimens can be adjusted from 600 to $1000 \mathrm{~Hz}$, but if the frequency is crossed $1000 \mathrm{~Hz}$, welding cannot be possible 
because of over excitation of specimens. Table 1 shows amplitude and acceleration with respect to frequency of specimens. Frequency, amplitude and acceleration of specimens have been tested by vibration tester. Fig. 2 shows dimensions of mild steel and stainless steel plates for butt welding.

Table.1. Frequency, acceleration and amplitude of specimen

\begin{tabular}{cccc}
\hline S No & $\begin{array}{c}\text { Frequency } \\
(\mathrm{Hz})\end{array}$ & $\begin{array}{c}\text { Acceleration } \\
\left(\mathrm{mm} / \mathrm{sec}^{2}\right)\end{array}$ & Amplitude $(\mathrm{mm})$ \\
\hline 1 & 600 & 15.41 & 0.235 \\
2 & 800 & 27.34 & 0.324 \\
3 & 1000 & 49.29 & 0.425 \\
\hline
\end{tabular}

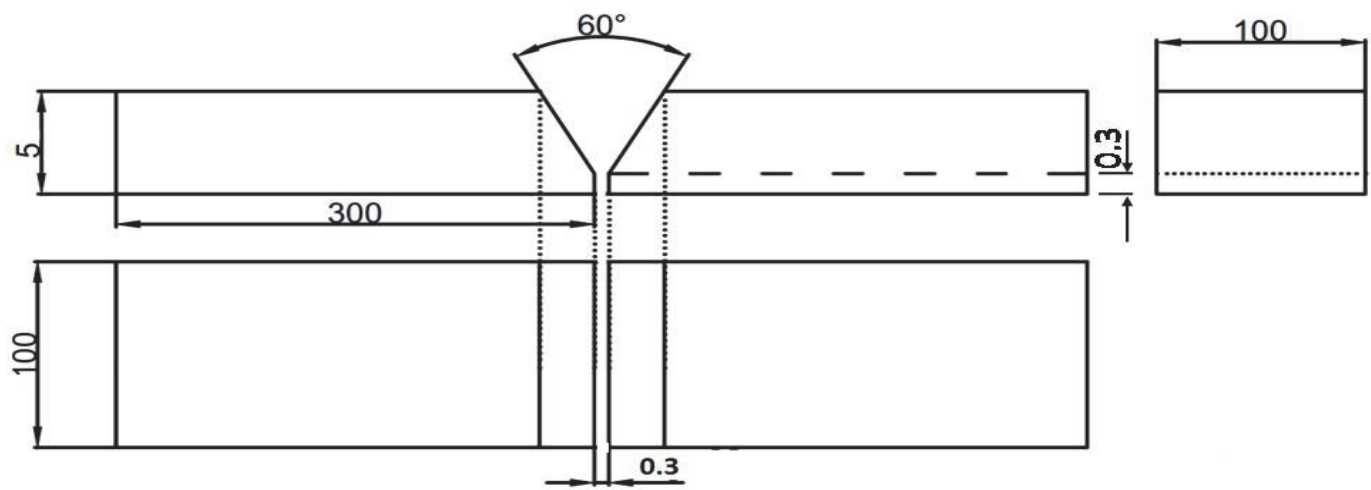

Fig. 2. Dimensions of Stainless steel and Mild steel plates for welding.

Fig. 3 shows TIG welding has been carried out with mechanical vibrations.

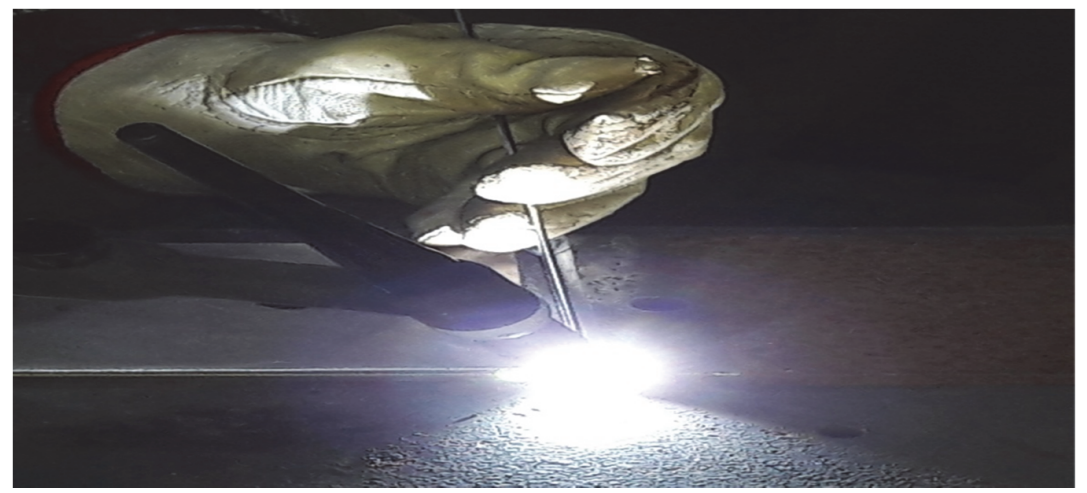

Fig. 3. TIG welding during vibrations.

\section{Results and discussions}

After vibratory TIG butt-welding process, hardness values have been measured by Rockwell hardness tester at different locations of weld bead region and heat affected zone (HAZ) of weldments produced with three different frequencies of specimens. Fig. 4 depicts the locations, where hardness values were measured. Table 2 and 3 show Rockwell hardness values along longitudinal direction of weld specimens and along weld bead direction of specimens. Figs. 5 and 6 show hardness increases with respect to increase in frequency of specimens.

Table 2. Hardness values (RHN) along longitudinal direction of weld specimens

\begin{tabular}{clllllll}
\hline Location & 1 & 2 & 3 & 4 & 5 & 6 & 7 \\
\hline WV & 63 & 69 & 62 & 76 & 60 & 61 & 60 \\
$600 \mathrm{~Hz}$ & 67 & 82 & 85 & 90 & 88 & 72 & 67 \\
$800 \mathrm{~Hz}$ & 72 & 85 & 88 & 94 & 92 & 80 & 81 \\
$1000 \mathrm{~Hz}$ & 80 & 87 & 98 & 99 & 97 & 93 & 90 \\
\hline
\end{tabular}




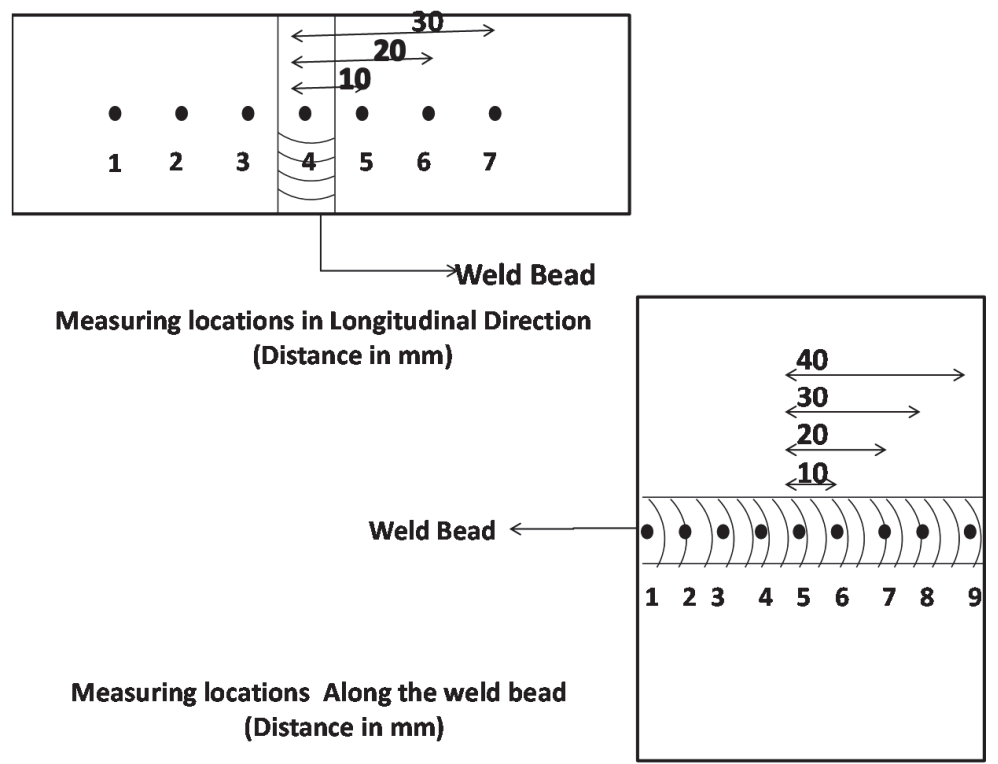

Fig. 4. Measuring locations along heat affected zone and weld bead.

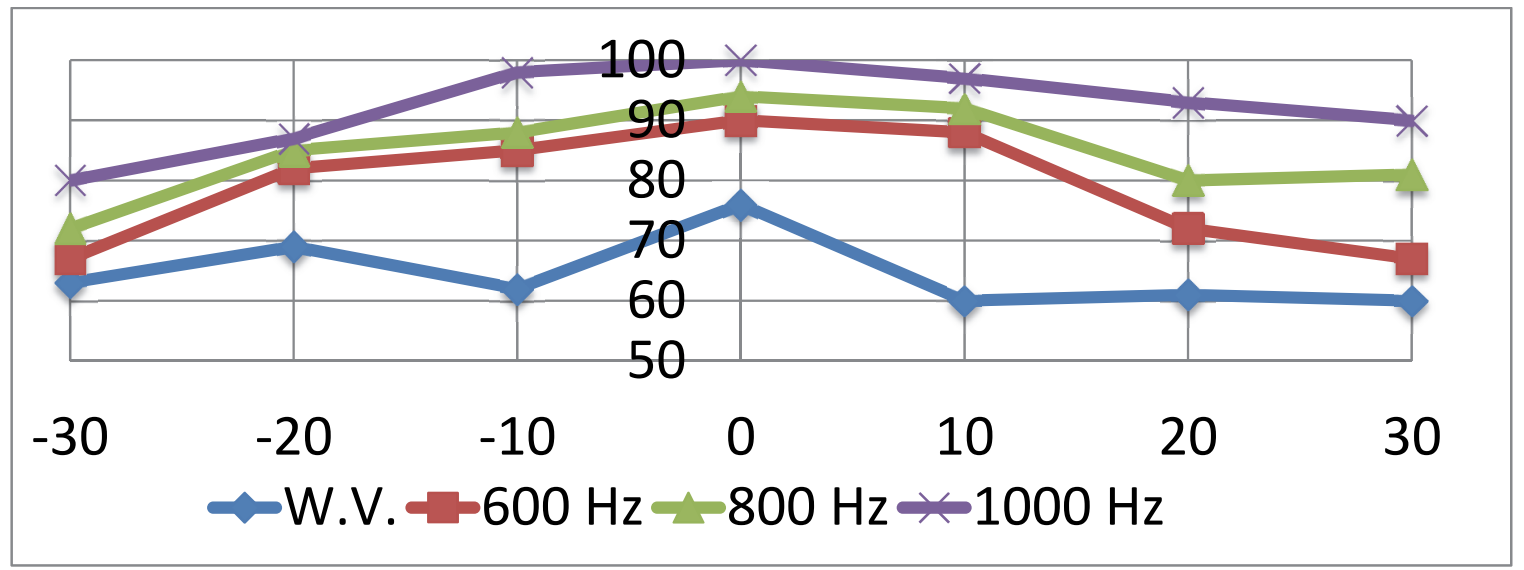

Fig. 5. Hardness values (RHN) along longitudinal direction of weld specimens.

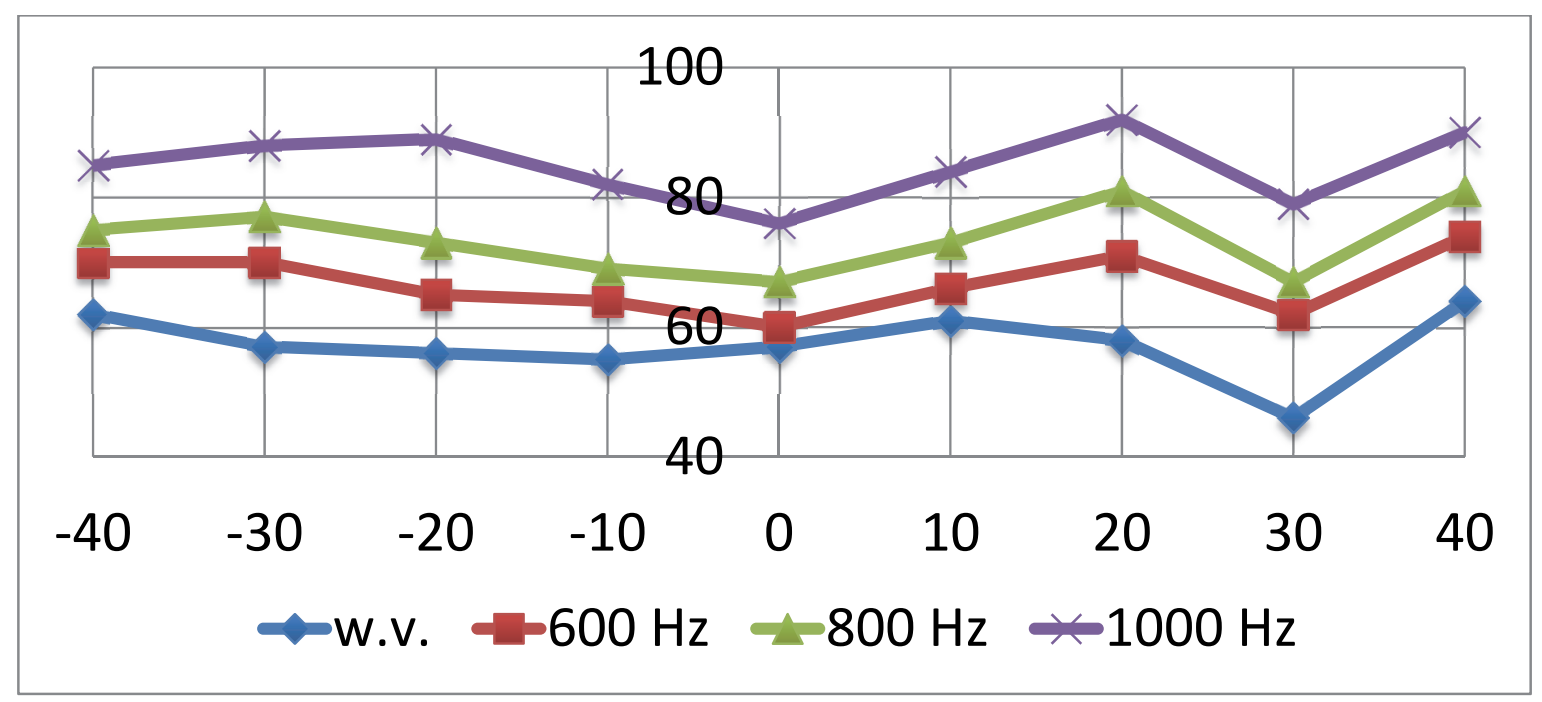

Fig. 6. Hardness values along weld bead direction 
Table 3. Hardness values (RHN) along the weld bead

\begin{tabular}{cccccccccc}
\hline Location & 1 & 2 & 3 & 4 & 5 & 6 & 7 & 8 & 9 \\
\hline WV & 62 & 57 & 56 & 55 & 57 & 61 & 58 & 46 & 64 \\
$600 \mathrm{~Hz}$ & 70 & 70 & 65 & 64 & 60 & 66 & 71 & 62 & 74 \\
$800 \mathrm{~Hz}$ & 75 & 77 & 73 & 69 & 67 & 73 & 81 & 67 & 81 \\
$1000 \mathrm{~Hz}$ & 85 & 88 & 89 & 82 & 76 & 84 & 92 & 79 & 90 \\
\hline
\end{tabular}

\section{Conclusion}

In the present study, welding of specimens has been carried out along with different frequency of vibrations during welding. Hardness of welded joints is increased with respect to increase in frequency along the weld bead and heat affected zone (HAZ). Based on the past literature, this is due to the fragmentation of long dendrites into small dendrites and better filler metal distribution, which leads to fine grain structure, is attained at the weld bead region.

\section{References}

Lu, Q., Chen, L., \& Ni, C. (2007). Improving welded valve quality by vibratory weld conditioning. Materials Science and Engineering: A, 457(1), 246-253.

Liu, J., Zhang, R. C., Jiang, L., He, Z. S., \& Tan, D. M. (2013). Research on vibration responses of railway steel bridge considering welding residual stress. In Applied Mechanics and Materials (Vol. 397, pp. 374-377). Trans Tech Publications.

Govindarao, P., Srinivasarao, P., Gopalakrishna, A., \& Sarkar, M. (2012). Affect of vibratory welding process to improve the mechanical properties of butt welded joints. International Journal of Modern Engineering Research, 2(4), 2766-70

Jurčius, A., Valiulis, A. V., \& Černašejus, O. (2010). Effects of vibration energy input on stress concentration in weld and heat-affected zone of S355J2 steel. In Solid State Phenomena (Vol. 165, pp. 73-78). Trans Tech Publications.

Munsi, A. S. M. Y., Waddell, A. J., \& Walker, C. A. (2001). The influence of vibratory treatment on the fatigue life of welds: A comparison with thermal stress relief. Strain, 37(4), 141-149.

Rao, P. G., Prasad, D. C., Sreeramulu, D. D., Babu, D. V. C., \& Rao, M. V. (2013). Determination Of Residual Stresses Of Welded Joints Prepared Under The Influence Of Mechanical Vibrations By Hole Drilling Method And Compared By Finite Element Analysis. International Journal of Mechanical Engineering \& Technology (IJMET), 4(2), 542-553.

Rao, P. G., Rao, P. S., \& Krishna, A. G. (2014a). Impact strength improvement of butt welded joints prepared by vibratory welding process. Journal of Manufacturing Technology Research, 6(3/4), 143.

Rao, P. G., Rao, P. S., \& Krishna, A. G. (2014b). Review on residual stresses in welded joints prepared under the influence of mechanical vibrations. Journal of Manufacturing Technology Research, 6(1/2), 33-40.

Rao, P. G., Rao, P. S., \& Krishna, A. G. (2015a). Mechanical properties improvement of weldments using vibratory welding system. Proceedings of the Institution of Mechanical Engineers, Part B: Journal of Engineering Manufacture, 229(5), 776-784.

Rao, P. G., Rao, P. S., \& Krishna, A. G. (2015b). Flexural strength improvement of welded joints prepared by vibratory welding process. International Journal of Manufacturing, Materials, and Mechanical Engineering (IJMMME), 5(4), 1-16.

Rao, P. G., Rao, P. S., \& Krishna, A. G. (2015c). Evaluation of bending strength of the vibratory welded joint using regression technique. International Journal of Offshore and Polar Engineering, 25(03), 227-230.

Teng, T. L., Fung, C. P., \& Chang, P. H. (2002). Effect of weld geometry and residual stresses on fatigue in buttwelded joints. International journal of pressure vessels and piping, 79(7), 467-482.

$\mathrm{Xu}$, J., Chen, L., \& Ni, C. (2007). Effect of vibratory weld conditioning on the residual stresses and distortion in multipass girth-butt welded pipes. International Journal of Pressure vessels and piping, 84(5), 298-303.

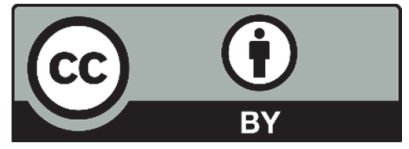

(C) 2017 by the authors; licensee Growing Science, Canada. This is an open access article distributed under the terms and conditions of the Creative Commons Attribution (CC-BY) license (http://creativecommons.org/licenses/by/4.0/). 